\title{
La fotografía de archivo como reflejo de la realidad
}

\author{
Rafael CROS LÓPEZ \\ rafaelcros@yahoo.es \\ Doctor en Ciencias de la Información por la Universidad Complutense de Madrid \\ Especializado en fotografía
}

Recibido: 03/06/2013

Aceptado: 19/06/2013

\section{RESUMEN}

La objetividad en la fotografía de prensa se define en cuanto a su relación con la realidad a la que representa. Hay un concepto básico de objetividad (la fotografía esta tomada directamente de la realidad, lugar o acontecimiento, a la que representa ) y un concepto abstracto de objetividad ( el significado de la fotografía coincide con la realidad que representa) Estos conceptos de objetividad dan lugar a cuatro tipos de relaciones: La imagen tiene una relación directa con el objeto y el mensaje que transmite coincide con la realidad del mismo; La imagen tiene una relación directa con el objeto pero el mensaje que transmite no coincide con la realidad del mismo; La imagen no tiene relación directa con el objeto pero el mensaje transmitido coincide con la realidad del mismo (fotos de archivo); La imagen no tiene relación con el objeto ni el mensaje que transmite coincide con la realidad (fotos de archivo).

Palabras clave: Fotografía, realidad, objetividad, ética, fotografía de archivo, Desembarco de Normandía, pie de foto, ABC, Arriba, Pueblo, Alcázar, Ya, Semana, Fotos, Mundo.

\section{Stock photography as a reflection of reality}

\begin{abstract}
Objectivity in press photography is defined in terms of its relationship to the reality it represents. There is a basic concept of objectivity (the photograph is taken directly from reality, place or event, which represents) and an abstract concept of objectivity (the meaning of photography coincides with the reality it represents) These concepts give rise objectivity four types of relationships: The image has a direct relationship with the object and the message coincides with the reality of it; The image has a direct relationship with the object, but the message conveyed does not match the reality of it; The picture has no direct relationship with the object, but the message conveyed match reality of it (stock photo); The picture is not related to the object or message coincides with reality (stock photo)

Keywords: Photography, reality, objectivity, ethics, Stock Photography, Normandy landings, photo caption, ABC, Arriba, Pueblo, El Alcazar, Ya, Semana, Fotos, Mundo.
\end{abstract}




\section{Concepto básico de objetividad fotográfica}

Todo el mundo que ve una fotografía publicada en un medio de comunicación, tanto en noticias como en reportajes, tiene una idea clara de lo que es una foto éticamente adecuada, la que refleja la realidad del acontecimiento al que representa. ¿Y como se representa fielmente esa realidad, lo que llamamos objetividad? El primer requisito que se le va a exigir a la imagen es que se tomara en el lugar y el momento del acontecimiento o noticia al que van a representar. El aquí y el ahora de la foto nos garantiza se supone que la imagen es objetiva, que se ajusta a la realidad de lo fotografiado.

\section{Concepto abstracto de objetividad}

Comprobar si una fotografía es objetiva parece una tarea sencilla, solo es necesario saber cuando y donde se tomo esa fotografía para poder asegurar si esta es o no real. Una mínima reflexión nos indica que esta afirmación es además de simplista inexacta. Lo primero que haría falta saber es ¿que es la realidad de un acontecimiento? Cada medio de comunicación, cada fotógrafo, o cada lector tiene su propia idea de la realidad, no se por tanto una referencia única e inamovible. Toda imagen va a ser manipulada desde el mismo momento en que se toma, por le fotógrafo tanto con operaciones técnicas (enfoque, encuadre...) como por el punto de vista que elige. Por el editor que vuelve a encuadrar la imagen y que le asigna un tamaño y una situación dentro de la publicación, al mismo tiempo que matiza su significado por medio de los textos como titulares o pies de foto con los que la relaciona. Y por último el propio lector que interpretará la foto de acuerdo a sus propias experiencias y valores.

Vamos a tomar entonces como objetividad de la imagen un concepto más abstracto pero más amplio que el mencionado anteriormente: una fotografía es más objetiva cuanto más cerca esta su lectura del acontecimiento al que representa, volviendo a insistir en lo variable que son ambos conceptos, "lectura" y "realidad". Con estas nociones básica y abstracta de objetividad vamos a tener las siguientes relaciones entre acontecimiento e imagen:

\section{- La imagen tiene una relación directa con el objeto y el mensaje que transmite coincide con la realidad del mismo}

Estamos ante la relación más directa entre imagen y realidad, la foto se toma en el momento y el lugar correspondiente al referente y nos transmite una imagen real del mismo. Esta sería la situación perfecta del periodismo gráfico, el fotógrafo está presente en el momento y lugar donde se produce el acontecimiento noticiable y es capaz de captar la naturaleza del mismo sin distorsionarla. No es difícil encontrar ejemplos claros de este tipo de imágenes en los medios de comunicación. Uno de los más claros está en la prensa deportiva, nadie puede discutir que las fotos se toman en el lugar y en el momento justo del acontecimiento, y que normalmente logra una 
imagen veraz de de lo que ha pasado en las pistas o campos de juego. Estos fotógrafos cuentan con la ventaja añadida de la especialización en su área concreta de trabajo, conocimiento de las condiciones ambientales y los lances del deporte que cubren que les hace alcanzar habitualmente un alto un nivel de calidad y tener la capacidad de captar el momento preciso, que pocas veces se ve en otras secciones.

\section{- La imagen tiene una relación directa con el objeto pero el mensaje que transmite no coincide con la realidad del mismo}

Es una de las formas más habituales de manipulación y las más controvertidas. Las fotos se han tomado directamente de la fuente de la noticia, pero ¿es verdad lo que cuentan? O dicho de otro modo, hasta que punto es verdad. Que la fotografía pertenezca al momento y el lugar que se indican sirve de coartada para asegurar que lo que cuenta es la cierto aunque no lo garantice. Un ejemplo típico es la cobertura gráfica que se da a cualquier manifestación, el escenario, los participantes destacados, las pancartas acreditan que la fotografía pertenece a un acto en concreto, pero como hemos comentado eso no basta; los comportamientos vandálicos que se dan en en muchas ocasiones, ¿definen al conjunto de los manifestantes?; o las banderas de España con el escudo preconstitucional que se ven en manifestaciones de ideología más conservadora, ¿son realmente representativas? Nos encontramos otra vez con la "inestable" objetividad, para muchos lectores la inclusión de unas u otras fotos es una forma perversa de manipulación mientras que para otros la manipulación consiste en omitirlas.

\section{- La imagen no tiene relación directa con el objeto pero el mensaje transmitido coincide con la realidad del mismo}

Nos encontramos con la situación contraria a la anterior, la fotografía no se corresponde con lo que representa, no hay una relación entre el objeto y la imagen, ni temporal ni de lugar, pero si transmite su realidad al lector. Esta situación es habitual cuando se utilizan fotos de archivo cuando porque no se tienen imágenes directas del objeto, o las que se tienen carecen de relevancia, ya sea por su falta de contenido o por su baja calidad. En esta situación es imprescindible la "manipulación" por parte de responsable de seleccionar las imágenes que se van a utilizar. La manipulación informativa no tiene por que acarrear la connotación negativa que habitualmente tiene, toda información (gráfica, escrita o filmada) es manipulada para poder convertirse en noticia, y en este caso que estamos mencionando entendemos que hay una actuación éticamente correcta en la selección y uso de las fotografias. Durante la guerra entre Irán e Irak durante los años $80^{\prime}$ s la escasez de material gráfico era patente, tanto por el hermetismo de ambos regímenes totalitarios como por la fuerte censura militar impuesta. Con este escenario, dos periodistas franceses Serge Daney y Christian Caujolle realizaron un curioso experimento, publicaron en las páginas del diario Libération dos fotografías muy similares, ambas imágenes se colocaron muy cerca la una de la otra una de ellas se pertenecía a la batalla de Verdum, librada 
durante la Primera Guerra Mundial, la segunda sí pertenecía realmente al conflicto entre Irán e Irak ${ }^{1}$. La similitud tanto del escenario de la guerra de trincheras como el aspecto desaliñado y de profundo cansancio que mostraban los protagonistas de ambas imágenes hizo que el mensaje que trasmitían fuera el mismo. Las dos fotografías respondían a las expectativas que los lectores tenían de la noticia que además coincidían con la realidad de la guerra.

\section{- La imagen no tiene relación con el objeto ni el mensaje que transmite coincide con la realidad}

Estaríamos en este caso ante la forma de manipulación menos ética, ni la fotografía se relaciona directamente con el acontecimiento ni la imagen que muestra se corresponde con la realidad del mismo. No es solamente que la imagen no tenga relación con la noticia, además va servir para condicionar la interpretación del lector. Es una imagen falsa. Esta ultima actuación resulta éticamente aun más reprobable cuando la función de la fotografía sobrepasa la mera complementación del texto para ser por si misma la el centro de la noticia; nos referimos a los casos en los que la imagen es la prueba de la veracidad de lo que se esta narrando. Esta imagen como actúa testigo, es el sueño de todo reportero gráfico, la que "levanta acta de la realidad", ya sea por casualidad, o por que cubre otro evento el fotógrafo esta en el momento y el sitio adecuado. Esto ocurrió por ejemplo la foto de Robert H. Jackson que muestra el momento del asesinato de Lee Harvey Oswald a manos de Jack Ruby el 24 de noviembre de $1963^{2}$

En otras ocasiones no es el fruto de la casualidad o la suerte lo que permite realizar la foto codiciada sino que es el fotógrafo el que consciente mente busca la imagen que sirva de prueba ante el público. En diciembre de 1937 los nacionales estaban absolutamente convencidos de que recobrarían Teruel, que había sido ocupada recientemente por los republicanos. Estaban tan seguros que no dudaron en comunicar oficialmente que la ciudad aragonesa estaba ya reconquistada. El corresponsal del New York Times en la zona nacional, William P. Carney, envió la crónica correspondiente a su periódico enriquecida con vividas descripciones del recibimiento brazo en alto de la población a las tropas de Franco. El mismo día de la publicación el otro corresponsal del New York Times, pero en el lado republicano, Herbert L. Mathews, junto a Robert Capa llegan a Teruel encontrándola aún en manos de los republicanos. El New York Times se vio obligado a publicar el desmentido de su propio corresponsal", con el famoso fotógrafo húngaro como "notario". El convencimiento cándido de que la fotografía no miente se viene fácilmente abajo cuando se utiliza una imagen falsa para ratificar una información o darle una mayor

\footnotetext{
${ }^{1}$ Fontcuberta, Joan. El beso de Judas. Fotografía y verdad. Pag 130. Gustavo Gili S.A.

${ }^{2}$ Parisfoto.com. http://www.parisphoto.com/losangeles/exhibitors/daniel-blau [07/05/2013]

${ }^{3}$ Armero, José Mario. España fue noticia, corresponsales extranjeros en la guerra civil española. Pag. 81-82. Sedmay Ediciones
} 
verosimilitud, "lo que digo es cierto, y aquí esta la imagen que lo demuestra".

Durante la guerra del Golfo, el presidente iraquí Sadam Husein mando incendiar los pozos de petróleo kuwaitíes antes de retirar sus tropas del país. Todas las cadenas de televisión occidentales mostraron las imágenes del desastre ecológico que esta actuación provocó sintetizadas con la imagen de un ave, un cormorán, con las alas impregnadas de petróleo. Pero la prueba gráfica de la maldad del dictador irakí correspondía en realidad al vertido provocado por el Petrolero Exxon Valdez en marzo de $1989^{4}$. Estas técnicas de falseamiento son habituales a nivel de redacción donde se recurre normalmente al archivo para buscar la realidad que más pueda interesar. No quiere decir esto que el fotógrafo no pueda no solo manipular la imagen sino también falsearla a conciencia, aunque estos casos sean más difíciles de identificar. Un ejemplo de esta actuación se puede encontrar aunque sea en la ficción; en la película Bajo el fuego, el reportero interpretado por Nick Nolte fotografía el cadáver de de un líder guerrillero nicaragüense haciéndole parecer vivo.

De todas estas relaciones entre Imagen y realidad se deduce que las tomadas del objeto o acontecimiento y que reflejan adecuadamente su realidad serian las éticamente más validas, y en el lado contrario estarían las fotografías que ni corresponden directamente con la realidad, ni muestran su naturaleza. Lo que se puede afirmar sin duda que es una falsedad. Entre estos dos polos opuestos tenemos las dos opciones anteriormente expuestas. A partir de aquí los juicios éticos se vuelven más complejos.

\section{Un ejemplo concreto: El Desembarco de Normandía en la prensa Española}

Al realizar la tesis doctoral, Cobertura fotográfica y representación de la II Guerra Mundial en la prensa gráfica española, y analizando las fotografías publicadas durante el desembarco de Normandía pude comprobar como las imágenes utilizadas se relacionaban con el acontecimiento por lo menos en tres de las cuatro formas anteriormente indicadas, no aprecié que ninguna foto ni correspondiera al acontecimiento ni falseara conscientemente su realidad.

El desarrollo de esta batalla es seguramente de los más conocidas de la historia, revisada tanto en libros como en películas o series de televisión, esto hace que sea fácil tener una idea general del contexto de los acontecimientos de los días 6 de junio y siguientes de 1944. Haciendo una síntesis muy breve, a primeras horas de la mañana las tropas norteamericanas, británicas y canadienses desembarcaron en las costas francesas de Normandía, lo que hasta que en cierta forma sorprendió a los alemanes que esperaban el desembarco por Calais, el punto más cercano a la costa inglesa, las operaciones más duras se produjeron en la playa denominada "Omaha" donde las tropas norteamericanas sufrieron fuertes pérdidas. Pese a todo, las cabezas de playa estaban estabilizadas para la tarde ese mismo día aunque los avances posteriores encontraron una fuerte resistencia por parte de las tropas alemanas.

\footnotetext{
${ }^{4}$ Fontcuberta, Joan. Op. cit. Pag 129.
} 
En el campo de batalla, los fotógrafos se suelen encontrar entre otros con dos problemas principales, la censura y la logística, los carretes tienen que llegar a retaguardia ser revelados y las fotos enviadas a través de las agencias hasta las distintas redacciones de diarios y revistas. Hay que recordar también que los medios españoles no se encuentran los "primeros de la lista" a la hora de recibir estas imágenes.

Aun así los servicios de prensa alemanes realizaron un enorme esfuerzo para que una fotografía de un grupo de prisioneros británicos capturados en los primeros momentos del desembarco pudiera llegar entre otros sitios a las redacciones de varios diarios españoles. $A B C$ y Arriba las publicaron al día siguiente y los diarios de tarde Pueblo y El Alcázar llegaron a publicarlas el mismo día de los desembarco, el 6 de junio.

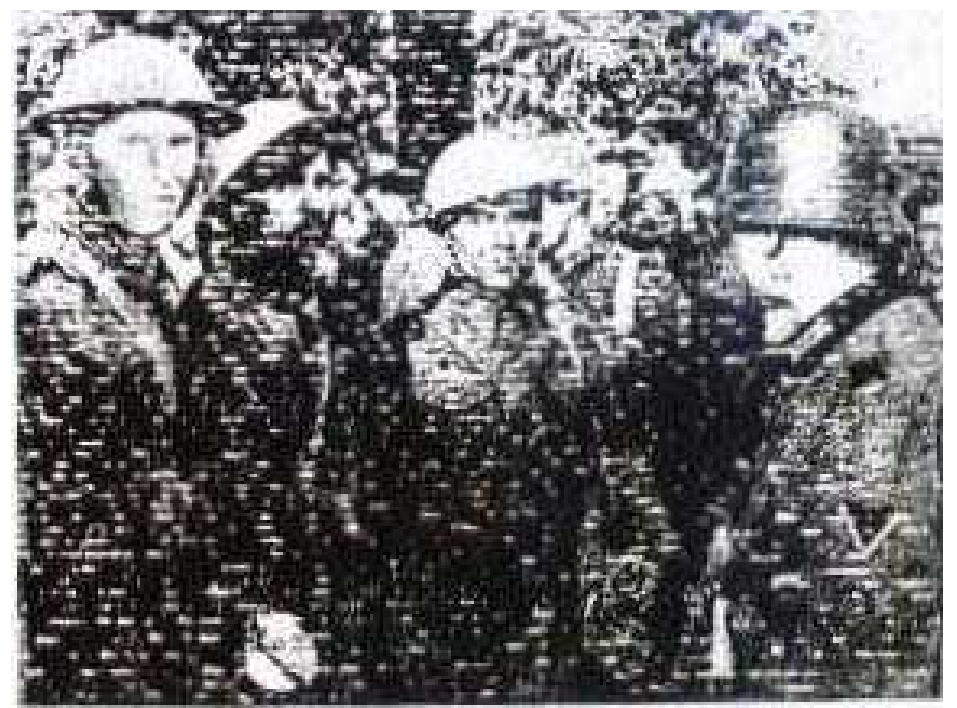

El Alcazar 6 de junio de 1944 Primera página

Estamos en un principio ante una fotografía que se ha tomado en el lugar y el momento un acontecimiento y que además refleja la realidad del mismo. Unos soldados británicos han sido capturados durante los primeros lances de la batalla. Un documento de un incuestionable valor periodístico, pero ¿realmente representa una visión completa de lo que está siendo el desembarco. El mensaje primero que la imagen da es de unos soldados aliados han sido hechos prisioneros. Pero el significado de la imagen va mucho más allá. Los prisioneros exhibidos ante la cámara son una muestra de superioridad de las tropas alemanas frente a los invasores, y en consecuencia nos esta sugiriendo que el desembarco no ha conseguido y que la situación es favorable para los alemanes. 
No se puede achacar a los diarios españoles que publicaron esta foto que tuvieran la intención dar una imagen favorable a los intereses alemanes, ya que poder publicar una imagen como esta en el momento que lo hicieron es algo a lo que ninguna redacción se hubiera resistido (a excepción de los medios de los países aliados directamente implicados). Se debe de reconocer que los pies de foto que acompañan a la imagen no resultan tendenciosos

$A B C:$...en otra aparecen un grupo de prisioneros ingleses (ni siquiera tiene un pie propio, lo comparte con las otras cinco fotos de la página)

7 de junio de 1944. Página 6.

El Alcazar: En la fotografia superior se observa un grupo de soldados ingleses que han sido capturados por las fuerzas alemanas en los primeros momentos de poner su pie en el continente...

6 de junio de 1944. Primera página.

Arriba: Un grupo de prisioneros de las fuerzas de invasión que ha caído en poder de los alemanes en las cercanías de Caen

7 de junio de 1944. Primera página.

Pueblo: Los primeros prisioneros aliados hechos por los alemanes 6 de junio de 1944. Primera página.

Queda descartada una manipulación interesada por parte de los medios españoles que se pueda considerar éticamente incorrecta, ya que aunque no se resisten a publicar la foto (como es lógico), no le dan con la información textual ninguna connotación favorable a la actuación alemana. Esta manipulación se ha producido en un contexto más complejo. El fotógrafo se encuentra, o le ponen ante una imagen que ha de ser retratada. Todo el esfuerzo para trastocar la visión de los lectores sobre las operaciones militares proviene de los servicios de propaganda alemanes. Vamos a dar por valido que la foto corresponda a prisioneros capturados el día del desembarco. Una de las primeras acciones que se han realizado ha sido fotografiarlos, hacer llegar el negativo a un laboratorio y la foto revelada a una instalación que disponga de un belinógrafo (instrumento que permite la transmisión de imágenes a través de al línea telefónica). Desde allí hay que hacerla llegar a las distintas agencias de todo el mundo, entre ellas a España, con el tiempo suficiente para que tanto Pueblo como El Alcázar puedan incluirla en su edición de tarde.

No podemos olvidar que la primera parte de esta operación se ha realizado en una zona de guerra en la que el control de las vías de comunicación por uno u otro bando es fundamental. Esta claro que los servicios de Joseph Goebbels han realizado un trabajo excelente, y que consideraban que esta foto se viera tanto en España como en otros países una prioridad casi militar.

En comparación con la efectividad alemana, la famosas fotos tomadas por Robert Capa durante la primera oleada de desembarcos en la playa "Omaha" llegaban al laboratorio de la revista Life en Inglaterra a las 9 de la noche del día 7 de junio, para 
revelarlas, pasar censura y ser enviadas a Estados Unidos a las 9 de la mañana del día siguiente. Las prisas hicieron que tres de los cuatro rollos quedaran totalmente inutilizados en la secadora y que del cuarto solo se pudieran salvar nueve fotos de las que seis se consideraron buenas ${ }^{5}$.

Junto con la imagen de los prisioneros aliados aparece otra fotografía también transmitida por belino. Como la anterior esta tomada en el lugar y el acontecimiento al que representa y que además no genera ninguna manipulación que se pueda considerar tendenciosa, se trata de una toma en la que unos cañones están abriendo fuego. La foto aparece tanto en la primera página de El Alcázar y Ya, además de en la 6 de Pueblo, mientras que El Alcázar no trata de dar connotación alguna a al imagen con el pie de foto "...La inferior nos muestra un aspecto de la imponente batalla que actualmente se libra en las costas de Francia", tanto Ya como Pueblo si utilizan la información escrita para orientar al lector aunque tampoco se puede tachar de una manipulación intencionada, "Las baterías costeras de la defensa alemana disparan contra las fuerzas de invasión en la madrugada del martes" en el diario católico y, "Esta foto radio recoge un momento de la enérgica reacción de las baterías alemanas en el Atlántico" en Pueblo. Lo que indican los pies de ambos diarios que concuerda con los acontecimientos que se estaban produciendo en Normandía.

Según todo esto, estamos ante una imagen que cumple con todos los requisitos éticos necesarios, está tomada en los en el lugar y en el momento adecuado y no busca mostrar una visión distorsionada de la realidad. Seria por tanto una imagen valida si no fuera porque la foto no tiene prácticamente ningún valor informativo, sin la indicación de los pies no se puede saber que es lo que realmente aparece en la fotografía, una serie de manchas blancas que deducimos que son los fogonazos de las baterías alemanas, pero que con la poca calidad de la foto junto con la perdida de definición de la transmisión por radio, (con sus características bandas horizontales) la hacen ilegible. No podemos olvidar que lo primero y más importante que ha de tener una fotografía de prensa es un contenido relevante.

Otras imágenes, como la de una vista de la flota de invasión tomada desde un avión británico publicada en $A B C$ y en $Y a$, también esta transmitida por radio y lo mismo que la anterior tiene muy mala calidad, hasta el punto de que ha tenido que ser retocada (burdamente) para poder llegar a publicarla. Pero a diferencia de la foto anterior, su contenido, una vista general del despliegue de la enorme flota de desembarco aliada, justifica por si mismo el esfuerzo de para hacerla llegar hasta las distintas agencias y redacciones como la inclusión en las paginas de los diarios que la utilizaron.

\footnotetext{
${ }^{5}$ Kershaw, Alex. Sangre y Champan, la vida y la época de Robert Capa. Pag 176-177. Debate
} 
$A B C 7$ de junio de 1944 Pag. 7, Ya 7 de junio de 1944 Primera página

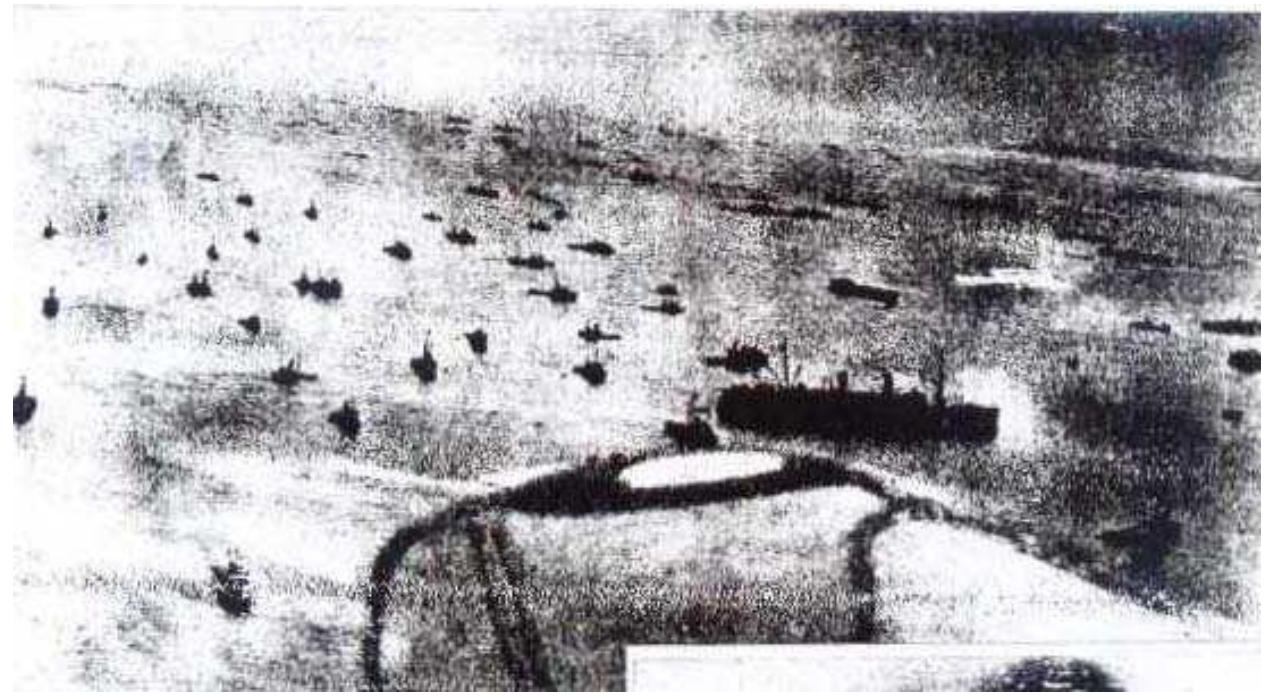

Hemos visto como la relación directa entre fotografía y realidad no garantiza unos resultados óptimos, ni en cuanto a la calidad de los contenidos ni en su capacidad de reflejar adecuadamente la imagen que de estos se debe de dar. Esto hace que se deban de sustituir en algunas ocasiones estas fotos "reales" por otras que puedan cumplir mejor su cometido, imágenes de archivo o de otras fuentes que puedan complementar la información escrita. Su utilización también genera notables problemas éticos, tanto en la selección de la imagen como por la información textual que la complementa.

Las consideraciones éticas a la hora de seleccionar una imagen dentro de fondo, un archivo, un banco de imágenes o cualquier otra fuente, van a ser similares a las que se tenían con las fotografías directamente tomadas del acontecimiento, es decir que la imagen que den del mismo coincida con la realidad de este.

Al poder seleccionar las imágenes de entre un fondo amplio, se cuenta con la ventaja de que al tener un mayor abanico de posibilidades entre las que poder optar, buscando un valor informativo y un comportamiento ético. Pero al mismo tiempo, y en referencia a esto último, la posibilidad de tergiversar la lectura que haga el lector de los acontecimientos a través de la fotografías va a ser mayor, y no se va a poder escudarse en que las fotos son válidas por el mero hecho de haberse realizado en el origen de la noticia. Las posibilidades y las responsabilidades del medio que las publica van a ser mayores. El otro factor importante a la hora de poder orientar el significado de la imagen son los textos que la van a acompañar, no solo en las fotos "de archivo" si no también aunque en menor medida en las directamente relacionadas con el acontecimiento. Por completa que sea una fotografía siempre va a precisar una referencia textual que permita interpretar el significado de la fotografía en relación al texto que acompaña. 
La relación entre imagen y texto no se inicia a partir de que los medios escritos empiezan a incluir entre sus páginas fotografías impresas. Desde mucho antes de la utilización de la imprenta los libros han contenido ilustraciones, y la primera publicación periódica en presentar una ilustración fue el periódico News Setter, editado en Boston, que incluyó una xilografía en el año 1707 que representaba una bandera del Reino Unido ${ }^{6}$. Las fotografías van ganando importancia en la prensa aunque en un principio solo sea como modelo para que los ilustradores puedan copiarlas e incluirlas en las páginas de periódicos y revistas. No va a ser hasta el cuatro de marzo de 1880 cuado el New York Daily Graphic consiga reproducir la primera ilustración fotográfica en semitonos (half-tone) o medias tintas ${ }^{7}$. Se puede afirmar que una buena parte de la historia de la "prensa gráfica" corresponde más a dibujantes que a fotógrafos, y que el papel de la imagen en el periodismo no ha sido históricamente la de una copia de la realidad sino una ilustración de la misma.

La inclusión de fotografías de archivo enlaza con esta tradición anterior a la fotografía impresa cuya función seria la de ilustrar más que informar, en su sentido más concreto, tal como el que refiere el diccionario de la R.A.E.

Ilustrar: Aclarar un punto o materia con palabras, imágenes, o de otro modo.

Cuando se tienen fotografías directas de un acontecimiento, estas nos van a marcar hasta cierta medida, cual va a ser la visión que estas van a dar del hecho al que directamente se refieren. Esta relación se invierte al trabajar con fotografías en otros momentos o lugares, el medio tiene una visión de lo que ha sido la noticia y busca las imágenes que más adecuadamente van a dar esa visión preconcebida.

Volvemos a buscar referencias en la prensa española durante la II Guerra Mundial. En noviembre de 1942 las tropas aliadas desembarcan en distintas zonas del norte de África, por falta de medios técnicos o por poca previsión de los servicios e prensa aliados, no se dispuso de fotografías de las operaciones en los medios españoles, ya fueran diarios o semanarios. La única solución fue utilizar imágenes que además de ser de archivo carecían de un mínimo valor representativo. Eran tomas de las ciudades que se habían visto implicadas o de nativos ataviados con las vestimentas típicas, imágenes más propias de un reportaje de viajes que de una batalla.

Las operaciones desembarcos masivos no habían sido fotografiadas anteriormente a excepción de contadas ocasiones como en Crimea en el siglo XIX o Gallipoli durante la I Guerra Mundial, y las diferencias de uniformes y equipos hacían inviable el utilizarlas en este conflicto.

Esta situación cambió radicalmente en junio de 1944 con los desembarcos de Normandía, no tanto por la disponibilidad de material grafico de primera mano, como por tener un importante cantidad de fotografias de archivo provenientes de las operaciones militares de Sicilia y de la Italia continental llevadas a cabo a lo largo de 1943, fotos que concordaban perfectamente cono los uniformes, equipos y transportes

\footnotetext{
${ }^{6}$ Alcoba López, Antonio. Periodismo gráfico (fotoperiodismo).Pag. 19-20 Editorial Fragua

${ }^{7}$ Sougez, Marie-Loup, Historia de la fotografia; pag. 316-317 Ediciones Cátedra S. A.
} 
utilizados en Normandía. Nos encontramos entonces con el siguiente dilema, ¿Cómo presentar la batalla de Normandía ante los lectores?

Existen también fotografías de archivo de procedencia alemana y que a diferencia de las aliadas cuentan con la ventaja de ser objetivamente más adecuadas que las de los aliados ya que corresponden a la zona del norte de Francia, zona de las operaciones y temporalmente son mas recientes que las tomadas en Italia el año anterior. Se trata principalmente de las imágenes de las defensas del llamado Muro del Atlántico construido para repeler acciones como la de Normandía.

Pero ¿que mensaje hacen llegar al lector unas fotos u otras?. Las poderosas defensas alemanas hablan no solo del poderío militar del Tercer Reich en la zona, sino que nos retraen hacia un momento anterior a la invasión, son fortalezas pensadas para repeler a los atacantes antes de que lleguen a las playas cuando todavía están en el mar o para no dejarles asentarse en la costa.

\section{Revista Semana pag. 913 de junio de 1944}

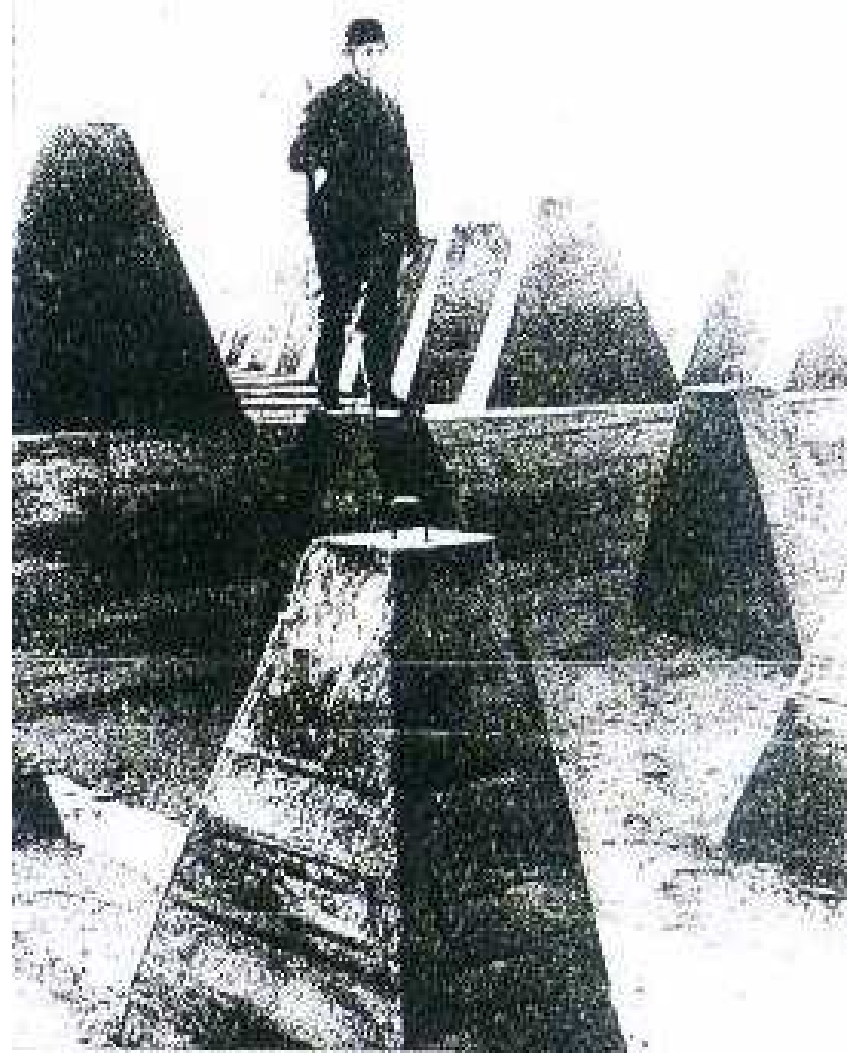


Las fotos tomadas de los desembarcos en el mediterráneo del año anterior dan la idea al lector de que los aliados están asentados en la playa de una forma estable, esta concepción de la batalla no puede calificarse de un exceso de optimismo por parte de los medios que optaron por ella, los aliados ha llegado a las playas normandas y se han mantenido en ellas, pero no se está afirmando que hayan pasado al interior del continente.

La simple elección de unas fotografías u otras dentro de las opciones que puede brindar un archivo van a cambiar de forma muy notable la concepción que el lector va a tener de un acontecimiento. Volvemos a entrar en el debate sobre que visión es la que más se adecua a la realidad, debate que casi siempre se suele saldar de la mima manera; la visión propia de cada uno es la correcta. En esta ocasión, al utilizar como ejemplo un acontecimiento histórico de sobra conocido nos da una perspectiva de lo que es la realidad bastante firme, esto nos permite analizar que tipo de fotografías se ajustan más a lo que realmente estaba ocurriendo, y comprobar si la cercanía ene el espacio y en el tiempo nos acercan más a la realidad.

$\mathrm{Si}$ analizamos éticamente la inclusión de unas fotos u otras (la intención de modificar la interpretación del lector con respecto a la realidad) podemos afirmar que las fotos de las defensas alemanas distorsionan la visión que el lector tiene de las operaciones militares. Desde nuestra perspectiva histórica sabemos como se desarrollaron los acontecimientos. La historia nos dice que el avance hacia el interior de Francia por parte de los aliados fue duro, pero que las cabezas de playa estaban estabilizadas para la tarde del mismo día 6 de junio. Por lo tanto las fotos de las defensas costeras como la reproducida aquí y publicada por Semana no serian pertinentes para ilustrar el desembarco de Normandía, provocan que el lector lea la noticia como si los aliados no hubieran mantenido las playas o hubieran sido rechazados por los alemanes antes de llegar.

Se puede alegar en defensa de los diarios, que incluyen estas fotos al día siguiente, (o incluso el mismo día del Desembarco, como Pueblo y el Alcazar), el desconocimiento a la hora del cierre de la edición de cómo se iban a desarrollar los acontecimientos y podían por tanto optar por una visión más pro alemana. Pero Semana, que como su nombre indica es un semanario, ha publicado la foto anterior el día 13 de junio, siete días después de del día $\mathrm{D}$. Ya no existe la incertidumbre de los primeros días y no se puede justificar la presencia de estas imágenes por motivos informativos. Algunas fuentes aseguraban que Adolf Hitler insistía que este desembarco era una distracción y que la invasión definitiva entraría por Calais, pero las evidencias de las operaciones anteriores descartaban esta hipótesis, pese a ello no solo Semana incluyo este tipo de fotos, la revista Mundo las sacó el día 11 y Fotos llego a sacarlas el 17.

La otra versión de los acontecimientos que transmiten las fotos tomadas a pie de playa, es la de que tras los primeros combates en la costa los aliados se han asentado en la cosa de forma estable. Aunque alguna de las fotografías de este tipo que se publican pueda estar tomada realmente en las playas de Normandía, la prontitud con 
que se tienen, la calidad y las condiciones climáticas que muestran hacen sospechar que sean fotografías correspondientes como hemos indicado en anteriores ocasiones a fotos de los desembarcos del Mediterráneo de 1943.

Los uniformes el equipamiento básico y los vehículos, tanto de transporte como militares son muy similares en uno y otro escenario, así como los paisajes. Otras fotos similares, las del frente del Pacífico donde tanbien hubo operaciones de desembarco pero las condiciones tropicales de la zona presentaban un paisaje con una vegetación característica totalmente diferente a la del norte de Europa y unos uniformes adecuados a este tipo de clima. No quiere decir esto que muchas fotografías, dependiendo de los elementos que muestre no puedan intercambiarse entre un escenario u otro si se es cuidadoso con la selección.

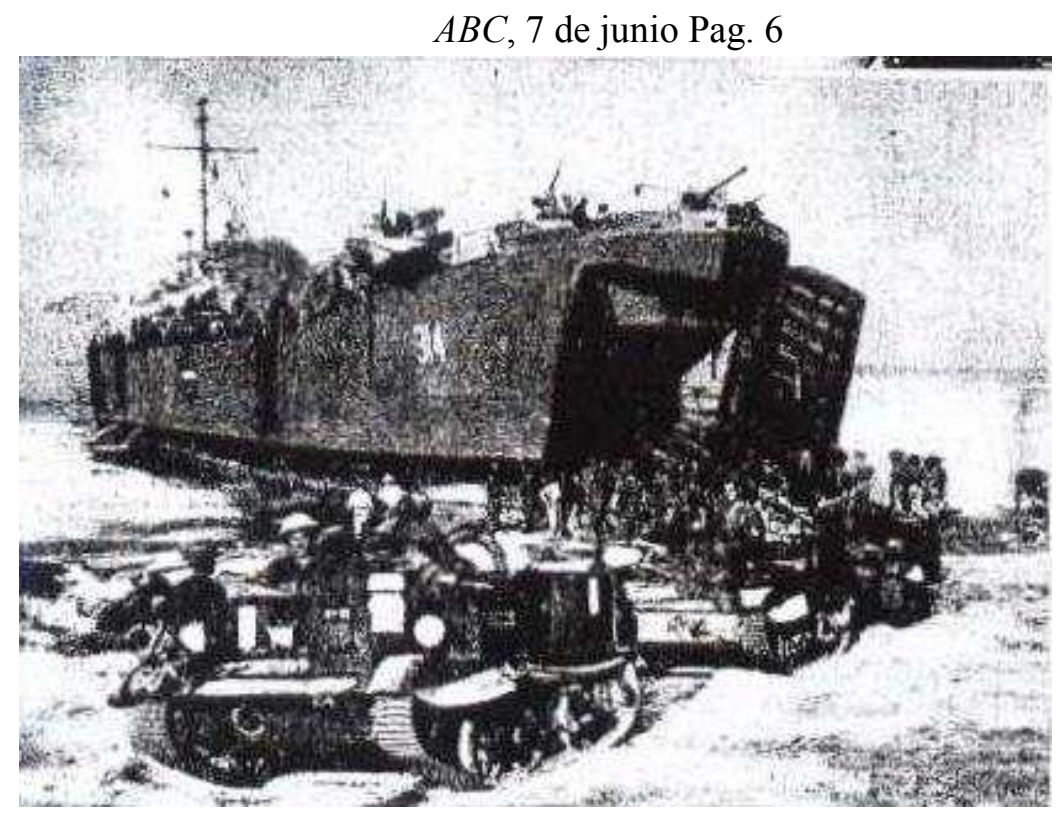

El navío de la fotografía es el USS LST (Landing Ship Tank) 314. Este barco efectivamente participo en las operaciones de desembarco, pero en la segunda oleada del día 7 de junio, el mismo día que se publica esta fotografía en $A B C$. Por lo que no pudo ser tomada en Normandía. En realidad la imagen se hizo en septiembre de 1943 en Salerno, Italia ${ }^{8}$.

Mencionamos antes que las condiciones climáticas pueden hacer dudar sobre a que escenario pertenecen las imágenes, más adelante se vera que algunas fotos que pasan por ser de Normandía se puede deducir que muestran una luz más propia del

\footnotetext{
${ }^{8}$ Wrecksite. eu. http://www.wrecksite.eu/wreck.aspx?2328 [22/05/2013]
} 
Mediterráneo. Es cierto que en la fotografía en blanco y negro no se puede apreciar la temperatura de color (que nos mostraría la calidez de la luz que diferencia el norte del sur de Europa), y que la película pancromática habitual refleja mal los tonos azules, aclarándolos en exceso, por lo que es difícil diferenciar entre un cielo nublado como el de Normandía de un soleado día de verano en Italia. Pero lo que si son claramente diferentes entre uno y otro escenario son las luces, y sobre todo las sombras, mucho más duras en los días soleados.

Un análisis superficial de la situación militar de los días posteriores al 6 de junio de 1944 nos va a confirmar que la visión más acertada del desarrollo de los hechos la van a dar las fotografías tomadas en las playas italianas el año anterior ante que las que se sacaron de las costas francesas en fechas cercanas a la invasión, por muy subjetivas que puedan ser las interpretaciones tanto de los medios como de los lectores de la época.

Quiere decir esto que había un posicionamiento antagónico entre los distintos medios españoles, ni mucho menos, lo cierto es que la mayoría de los medios que incluían fotos de los desembarcos, principalmente los semanarios, mezclaban unas y otras, así lo hacen Semana, Mundo o Fotos, los diarios recurrieron menos a este tipo de imágenes.

\section{La relevancia de los pies de foto}

Hasta ahora hemos hablado de las imágenes como un elemento informativo autónomo cuando en realidad el mensaje que transmiten está relacionado y condicionado por la información textual u otras imágenes que las acompañan. Los textos que más van a condicionar el significado de la imagen vana a ser primeramente los más vistosos, los titulares, lo primero que se va llegar al lector junto con las propias imágenes y los pies de foto. Al contrario de los titulares, los pies son menos visibles, suelen ir en un cuerpo de letra más pequeño que el bloque principal de información, pero al tratar directamente de la propia foto a la que acompañan, es el elemento en el que el lector va a buscar las referencias necesarias para poder interpretar el significado de la imagen. ¿Como se relacionan los pies de foto con las imágenes? Se pueden encuadrar en tres modelos principales

Descriptivo: Se limita a relatar lo que se ve en la imagen indica al lector que es lo que ve cuando sus conocimientos o contexto no le permiten identificarlo directamente. Esta información no tiene por que ser siempre cierta

Interpretativo: se apoya en la imagen para dar un significado, más amplio de la que esta tiene por si misma, o directamente modifica conscientemente el significado de esta.

Independiente: el texto del pie no establece una relación clara con la imagen o esta es secundaria. Este tipo de pie no es tan habitual como los otros dos mencionados.

En general los pies de las fotos españolas de Normandía cuentan con imágenes que como hemos visto conllevan su propia interpretación. Además de un valor 
informativo contundente que las interpretaciones de los pies de foto no van a variar. Como vimos con la fotografía de los prisioneros aliados, la foto habla por si sola y los textos de los pies simplemente confirman lo que el lector intuye, que son prisioneros capturados al poco de poner los pies en el continente.

En las fotografías de las defensas costeras los distintos medios utilizan los pies de forma similar, son descripciones de las edificaciones y sistemas de defensa aleganas en las que se ve una moderada alabanza a su presumible efectividad antes posibles ataques desde la costa.

"La costa atlántica se halla defendida por macizas fortificaciones de cemento y tupidas redes de alambre de espino"

La revista de la agencia EFE Mundo, no disimula su admiración ante el aspecto de las defensas atlánticas una actitud por parte de la revista nada reprochable si se hubiera publicado antes de los desembarcos. El problema es que se publica el día 11 de junio. Más evidente resulta esta actuación en la revista Fotos que con su barroco estilo falangista utiliza la descripción de una de las imágenes de las defensas para no solo para elogiar su fortaleza sino directamente coloca un pequeño articulo sobre los combates alrededor de estas construcciones, en fechas tan tardías como el 17 de junio.

"La muralla del Atlántico no es un mito", ha dicho el corresponsal de la Agencia oficiosa inglesa, Y ciertamente que ha soportado pruebas inmensas "Durante los últimos días -declara un despacho de Londres- las Marinas aliadas han realizado el bombardeo naval más intenso y prolongado de la historia". Los testimonios son pues, del máximo valor, ya que proceden de sus adversarios. El fuerte de Marcouf está aislado desde hace diez días y sigue defendiéndose, y en el propio parte alemán se citan, por su actuación, una serie de fortines costeros. Por lo demás, en el resto del extenso litoral, la existencia de las defensas alemanas ha impedido el desembarco aliado.

Es muy posible que los acontecimientos que relata Fotos sean ciertos y algunas de las fortificaciones alemanas sigan resistiendo, y por supuesto no vamos a dudar de que las fotografías sean de esas fortificaciones, pero está claro que crean una visión distorsionada de la realidad, sin que pueda dudarse en un principio de su pertinencia.

Analizamos ahora los pies de las fotos aliadas de las playas, en esta ocasión tenemos dudas más que razonables de que las fotos sean realmente del desembarco de Normandía sobre todo las de los diarios. Con los pies de foto de estas imágenes ocurre algo similar a los de las fortificaciones, no van a dar una visión diferente a la que dan las imágenes por si mismas, pero a diferencia de las anteriores va a ser la adecuada al momento de la publicación aun no siendo del lugar de los combates. Nos encontramos con imágenes atractivas a nivel periodístico además de concordantes con la realidad. Tampoco ahora los textos de los pies van a forzar la interpretación del lector ante las imágenes. El problema ético con el que se van a encontrar es otro. ¿Se debe de indicar que la imagen no corresponde realmente al desembarco de Normandía, informado de su origen? 
Fuerzas del Ejército americano durante unas maniobras que han llevado a cabo como entrenamiento para la invasión

Arriba, pese a contar con una buena imagen opta por reconocer que realmente se tomo durante unas maniobras previas al desembarco en su página 3 del día 7 de junio. Es una respuesta ética, de reconocimiento ante sus lectores, ya que ante el mensaje de la noticia este reconocimiento no varía su significado, que como hemos indicado repetidamente se va a refirmar más con este tipo de imágenes. Existe una opción más diplomática, no reconocer que las fotos son de archivo pero teniendo cuidado de no presentarlas como autenticas imágenes propias del desembarco, como hace Pueblo con una interesante foto publicada el mismo día 6 en su pagina 2.

Soldados de Infantería de Marina desembarcan

Eso es lo que se ve en la foto, ni más ni menos, no se engaña a nadie porque no se vincula expresamente al acontecimiento. La foto y articulo se complementan y aumentan su significado al interactuar entre si. El periódico da pistas al lector de que no es una foto autentica, un pie ambiguo, o no aparecer en primera página, indican que no estamos ante un documento gráfico de primer orden. Pero la primera impresión que la foto junto con la noticia ha provocado en el lector es igual de contundente que si la foto hubiera sido autentica. Es más ético reconocer claramente que la foto es de otro momento y lugar como hace Arriba, pero ese reconocimiento rompe la relación entre imagen y texto haciéndole perder una parte de la veracidad que realmente tiene.

Una actuación muy distinta es la que se aprecia en el diario $Y a$, con su foto de primera página del día 7 de junio.

Soldados expedicionarios apiñados en las lanchas de desembarco en la madrugada de ayer

Al diferencia de Pueblo el Ya coloca la foto en portada, indica que estamos ante un documento relevante, juega con un margen de tiempo mayor que nos hace más creíble la imagen y nos asegura que los soldados que vemos en la foto estaban a punto de desembarcar en Normandía, con todo esto estaríamos ante una foto de gran valor informativo. Su mala calidad y las marcas en forma de líneas claras, típicas de la transmisión por belino, le dan aún más credibilidad.

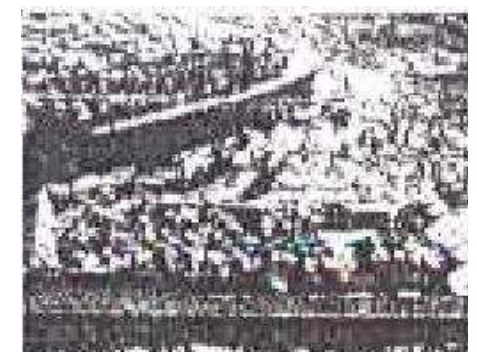

$Y a, 7$ de junio de 1944. Primera página 
En el caso del $Y a$ la fotografía no sirve para ilustrar una información, es una prueba de lo que está ocurriendo en las playas un papel mucho más contundente y comprometido que lo que se ha comentado hasta ahora. En este caso si la foto no corresponde con la información que acompaña estamos ante un uso éticamente inadecuado de la imagen. Al igual que el cormorán cubierto de petróleo de Kuwait lo que vemos una falsedad, el periódico no la utiliza para ilustrar una información, la utiliza como prueba de la veracidad de lo que esta narrando.

Afirmar que una foto con mas de sesenta años es falsa es muy arriesgado (con fotografías más conocidas los debates se han alargado durante años). Pero la información del pie es tan concreta que permite dudas más que razonables, sobre todo en lo que afirma categóricamente. Según el periódico la foto corresponde a las primeras horas del desembarco. En la foto aunque con una pésima calidad se intuyen las lanchas y a los soldados que las ocupan. Tanto la cabeza de los soldados como los bordes superiores de las lanchas aparecen intensamente iluminados y con un fuerte contraste con las zonas de sombra, también son muy intensos los reflejos del agua. Esta luz nos dice dos cosas, primero que estamos durante las horas centrales del día y que el cielo esta despejado, ni una cosa ni otra se dio durante las primeras oleadas de la invasión.

Las marcas de transmisión por radio que se aprecian hacen pensar sin embargo que la foto se mando desde las agencias aliadas identificada como perteneciente a las operaciones de desembarco en una maniobra de propaganda similar a la de las agencias alemanas con la foto de los prisioneros británicos.

Las fotos de archivo tienen un enorme valor no solo a la hora de recuperar su contexto original sino como herramienta de mejora tanto estética como informativa de los medios que los utilizan. A su vez también generan cuestiones éticas propias cuando la imagen no se corresponde físicamente con la información a la que acompaña. Como hemos visto, muchos de estos dilemas que se plantean con la manipulación de la percepción del, lector son comunes a los que se pueden generar con las fotos tomadas en el momento y el lugar de la noticia. El dilema propio de estas imágenes, partiendo de la base de una adecuada participación en el contexto, será el de admitir que las imágenes no se corresponden con la información, sabiendo que este reconocimiento hace que la imagen pierda buena parte de su efectividad.

En el uso de las imágenes sin relación física hay un punto que no se debe nunca traspasar que es el inducir al lector que la imagen que tiene una función ilustrativa la vea como una imagen testimonial. Como prueba de lo que se escribe. 